\title{
Characterization of thermosensitive autolytic mutants from diploid Saccharomyces cerevisiae
}

\author{
Víctor J. Cid, Miguel Sánchez and César Nombela
}

Departamento de

Microbiología II, Facultad de Farmacia, Universidad Complutense, 28040-Madrid, Spain
Author for correspondence: César Nombela. Tel: +341394 1744. Fax: + 3413941745.

In order to carry out a systematic search for mutants affected in cell integrity, the diploid strain Saccharomyces cerevisiae D1 was subjected to mutagenesis with ethyl methane sulphonate (EMS), and mutant clones were screened for thermosensitive autolytic phenotypes. The screening was based on examination of cell populations, from individual mutant clones, stained with propidium iodide to establish the proportion of cells lysing under nonpermissive conditions by means of flow cytometry. Osmotic remediation of the autolytic phenotype in the presence of $1 \mathrm{M}$ sorbitol was also checked. Out of 13300 clones surviving mutagenesis, 34 were confirmed to be thermosensitive autolytic and 7 of them showed some osmotic complementation with regard to growth and cell lysis. The osmotic remediation in the other strains was negligible or affected only one of the two parameters. The expression of the mutant phenotype in the strains isolated led to a sporulation defect ( $40 \%$ of the strains) and significant alterations in morphology, such as cells in chains $(35 \%)$, altered buds $(25 \%)$ that eventually might elongate, round unbudded and highly vacuolated cells $(12 \%)$ and largesized cells $(12 \%)$. These observations show that alterations in functions related to cell integrity can be correlated with an altered morphology. Genetic analysis of the mutant strains that could sporulate showed that in many instances the mutant phenotype was the result of more than one mutation, the mutations being individually recessive. However, at least one mutant strain, 933, carried a single mendelian mutation that was dominant in the diploid but haploid segregants were non-viable. Dominance of this mutation was also confirmed in tetraploids obtained by means of protoplast fusion.

Keywords: Saccharomyces cerevisiae, thermosensitive autolytic mutants, osmotic stability, cell integrity

\section{INTRODUCTION}

Yeast cell integrity during cell division depends on the formation of an osmotically stable cell wall, a process that obviously has to be connected to the development of the cell cycle itself. The characterization of yeast mutants altered in cell integrity provides some insight regarding the genetic control of the process and reveals the involvement of a complex set of genes. Among the aforementioned types of mutants are those that display a thermosensitive autolytic phenotype, leading to the formation of an osmotically unstable cell wall when grown at the non-permissive temperature. These mutants have not only been isolated from Saccharomyces cerevisiae

Abbreviations: EMS, ethyl methane sulphonate; PI, propidium iodide.
(Cabib \& Duran, 1975) but from other yeasts such as Scbizosaccharomyces pombe (Ribas et al., 1991) or Candida albicans (Payton \& de Tiani, 1990) and from filamentous fungi such as Aspergillus nidulans (Borgia \& Dodge, 1992). The possibility of characterizing autolytic mutants as being osmotic-remedial, when the phenotypic defect can be complemented by osmotic stabilization (with $1 \mathrm{M}$ sorbitol), or non-osmotic-remedial (De la Fuente et al., 1992), provides initial indications as to whether the genetic defect is more or less directly related to cell wall functions. At least another two types of yeast mutants altered in cell wall functions have been described. One is the fragile mutant that requires osmotic stabilization for normal growth at any temperature but it lyses spontaneously on transfer to hypotonic solution (Venkov et al., 1974). The gene affected in this mutant, namely $S R B 1$, has been cloned but the details on the characterization of 
the corresponding protein product remain to be revealed (Stateva et al., 1991). The other type is represented by the mutants defective in osmoregulation $\left(\mathrm{Osm}^{\mathrm{s}}\right)$ so that the cells do not grow in high-osmolarity medium (Brewster $e t$ al., 1993).

Several recent observations are beginning to shed some light on the genetic controls of the functions involved. For example, several protein kinase genes have been shown to be critical for the generation of an osmotically stable cell wall so that the cells deficient in the corresponding gene are only viable in osmotically stabilized media. Among these $S$. cerevisiae protein kinase genes, whose deletion leads to an autolytic osmotic-remedial phenotype, are $S L T 2$ (Torres et al., 1991), which codes for a mitogen-activated protein kinase (MAP-kinase) (Martin et al., 1993), BCK1/SLK1 (Lee \& Levin, 1992; Costigan et al., 1992) and PKC1 (Levin et al., 1990; Paravicini et al., 1992), which seem to be part of a cascade of phosphorylation reactions (Lee et al., 1993). The step(s) regulated by this cascade are eventually critical for cell wall formation: PKC1 defective cells have been shown to display differences in the appearance of the cell wall by electron microscopy (Paravicini et al., 1992). However, the specific event(s) regulated by this kinase cascade as well as the substrate(s) of the corresponding phosphorylation reactions remain to be established. The functions related to osmoregulation also seem to be controlled by MAPkinase genes such as HOG1 and PBS2 (Brewster et al., 1993) that could participate in another cascade.

Studies on autolytic mutants have so far been carried out in haploid strains and the mutations analysed are recessive in heterozygous diploids. However, the mutants described so far probably account for a limited number of genes involved in these functions, and many more are still unknown. In order to develop a wider picture of phenomena related to cell wall integrity, we have undertaken the systematic isolation of a set of autolytic mutants from a $S$. cerevisiae diploid strain with the aim of identifying dominant mutations altering cell integrity and cell wall osmotic stability.

Table 1. Strains of Saccharomyces cerevisiae used in this study

\begin{tabular}{|c|c|c|}
\hline Strain & Genotype & Source* \\
\hline US $92 / 1 \mathrm{~A}$ & $M A T \alpha$ ura 3 leu 2 trp 1 bis 3 & F. del Rey \\
\hline L839 & $M A T \mathbf{a}$ ura 3 leu 2 bis 1 & F. del Rey \\
\hline D1 & $\begin{array}{c}M A T \mathbf{a} / M A T \alpha \text { ura3/ura3 } \\
\text { leu2/leu2 trp1/TRP1 } \\
\text { bis } 1 / \text { HIS1 bis } 3 / \text { HIS3 }\end{array}$ & This work \\
\hline 373 & $M A T \mathbf{a}$ ade 2 & A. Jimenez \\
\hline $\mathrm{S} 288 \mathrm{C}$ & $M A T \alpha$ mal gal2 & M. O. Halvorson \\
\hline DV373 & $M A T \mathbf{a} / M A T \alpha$ ade $2 / a d e 2$ & This work \\
\hline
\end{tabular}

*F. del Rey, University of Salamanca; A. Jimenez, Autonomous University, Madrid; M. O. Halvorson, Brandeis University.

\section{METHODS}

Strains and growth conditions. The haploid and diploid strains used are indicated in Table 1. The general-purpose media used in this work were YEPD liquid medium or agar, containing $1 \%$ $(\mathrm{w} / \mathrm{v})$ yeast extract, $2 \%(\mathrm{w} / \mathrm{v})$ glucose, $2 \%(\mathrm{w} / \mathrm{v})$ peptone, and $2 \%(\mathrm{w} / \mathrm{v})$ agar when appropriate. For the assessment of auxotrophic markers, plates of minimal medium [MM: $2 \%$ $(\mathrm{w} / \mathrm{v})$ glucose, $0.7 \%$ Difco yeast nitrogen base without amino acids, $2 \%(\mathrm{w} / \mathrm{v})$ agar] plus the required mixture of amino acids were prepared. Growth temperatures in these media were usually $24^{\circ} \mathrm{C}$ when permissive conditions were required, and $37{ }^{\circ} \mathrm{C}$ for non-permissive conditions. $\mathrm{MM}$ was also used for diploid selection after mating of auxotrophic haploid strains when complementation of the nutritional markers was expected. Sporulation was achieved by growing diploid cells in PSM [presporulation medium: $1 \%(\mathrm{w} / \mathrm{v})$ yeast extract, $3 \%(\mathrm{w} / \mathrm{v})$ meat extract, $5 \%(\mathrm{w} / \mathrm{v})$ glucose], for $1-2 \mathrm{~d}$, and transferring them to SM [sporulation medium: $1 \%(\mathrm{w} / \mathrm{v})$ sodium acetate, $0.25 \%$ yeast extract, $0 \cdot 1 \%$ glucose]. When osmotic stabilization was required, $1 \mathrm{M}$ sorbitol was added to any liquid or agar medium.

Mutagenesis and selection of mutants. Mutagenesis was carried out with EMS (ethyl methane sulphonate, Sigma) and conditions were adjusted after several trials to achieve a survival rate of approximately $30 \%$. Exponential-phase cells, grown in YEPD at $28^{\circ} \mathrm{C}$, were adjusted to a concentration of $2 \times 10^{8}$ cells $\mathrm{ml}^{-1}$, washed twice with $0 \cdot 1 \mathrm{M}$ phosphate buffer $\mathrm{pH} 7.0$ and diluted with the same buffer to a concentration of $6 \times 10^{7}$ cells $\mathrm{ml}^{-1}$. Then $25 \mathrm{ml}$ EMS was added to $1.3 \mathrm{ml}$ of the cell suspension and incubated at $30^{\circ} \mathrm{C}$ for $10 \mathrm{~min}$ with gentle shaking. Finally, $200 \mathrm{ml}$ of the mutagenized suspension were poured into a tube containing $8 \mathrm{ml} 5 \%(\mathrm{w} / \mathrm{v})$ sodium thiosulphate in order to neutralize the mutagen, and a $1 / 100$ dilution of this suspension was plated on YEPD agar and incubated for 4-5 d at $24^{\circ} \mathrm{C}$. As a control of viability, another sample of the initial suspension was taken through all these steps, except the EMS treatment, and plated to obtain the figures corresponding to $100 \%$ viability.

Selection of thermosensitive autolytic mutants was carried out by replica plating on YEPD medium supplemented with BCIP (5-bromo-4-chloro-3-indolyl phosphate, Sigma) and incubating the plates for $2 \mathrm{~d}$ at $37^{\circ} \mathrm{C}$. This substrate is specifically recognized by the intracellular enzyme alkaline phosphatase, turning the colonies blue when the enzyme is released from the cytosol to the medium due to the loss of cell integrity.

Fluorescence microscopy. Propidium iodide (PI; 0.005\%) was added to the suspension medium in order to observe alterations in cell integrity by means of UV light microscopy. Only cells with impaired membranes or cell walls become permeable to the fluorochrome, which attaches to nucleic acids (De la Fuente et al., 1992). The observation of nuclei by staining with chromomycin (1 mg in $2.5 \mathrm{ml}$ ethanol/water, $1: 1$ ) was performed by adding a drop of chromomycin solution to ethanol-fixed cells. Calcofluor white specifically stains chitin in the fungal cell wall (Roncero et al., 1988). It was used at a concentration of $100 \mathrm{mg} \mathrm{ml}^{-1}$. Both chromomycin- and calcofluor-stained preparations were observed and photographed under a Nikon UV light fluorescence microscope.

Yeast genetic procedures. Crosses between strains of opposite mating types were made by mixing colonies of both types on the surface of a YEPD plate, incubating for 5-6 h, sorting the zygotes by micromanipulation and growing them in PSM. Dissection of asci was carried out by micromanipulation on YEPD medium slices, after partial digestion of the walls of the asci by treatment with NEE-154 Glusulase (DuPont): $10 \mathrm{ml}$ 
Table 2. Comparative phenotypes of the thermosensitive diploid mutants

\begin{tabular}{|c|c|c|c|c|c|}
\hline Mutant & Sporulation & $\begin{array}{l}\text { Growth } \\
\text { at } 37^{\circ} \mathbf{C}^{*}\end{array}$ & $\begin{array}{l}\text { Percentage of } \\
\text { surviving } \\
\text { cells at } 37^{\circ} \mathrm{C} \dagger\end{array}$ & $\begin{array}{c}\text { Remediation by } \\
1 \mathrm{M} \text { sorbitol } \neq\end{array}$ & Morphology at $37^{\circ} \mathrm{C}$ \\
\hline 111 & - & - & 30 & Partial on lysis & Abnormally round \\
\hline 201 & - & - & 20 & Partial on growth & Abnormally round \\
\hline 230 & - & Slow & 70 & - & Altered buds, short chains of cells \\
\hline 231 & - & - & 30 & + & Elongated buds, chains of cells \\
\hline 235 & + & + & 80 & Partial on lysis & Long and thin cells at $24^{\circ} \mathrm{C}$; chains at $37^{\circ} \mathrm{C}$ \\
\hline 238 & + & + & 70 & - & Chains and large cells \\
\hline 301 & - & Slow & 80 & - & Large abnormal cells \\
\hline 302 & + & Slow & 60 & - & Normal \\
\hline 327 & - & - & 10 & + & Extremely elongated buds \\
\hline 332 & - & - & 75 & + & Chains of cells \\
\hline 335 & - & Very slow & 75 & + & Short chains of cells occasionally \\
\hline 349 & + & - & 50 & + & Chains and large cells \\
\hline 354 & + & - & 50 & Very poor & Chains and large cells \\
\hline 356 & - & Very slow & 50 & Partial on growth & Altered buds \\
\hline 603 & - & + & 85 & Partial on lysis & Normal with occasional altered buds \\
\hline 606 & + & + & 30 & Partial on lysis & Chains and large cells \\
\hline 618 & + & - & 90 & - & Long chains of cells \\
\hline 623 & + & Slow & 50 & + & Large cells in chains \\
\hline 628 & Very poor & - & 10 & - & Normal \\
\hline 630 & Very poor & Slow & 50 & - & Normal \\
\hline 642 & + & + & 60 & - & Abundant small inviable cells \\
\hline 643 & - & Slow & 80 & - & Chains of cells and altered buds \\
\hline 646 & + & Slow & 25 & - & Large round cells \\
\hline 650 & + & - & 25 & Partial on lysis & Normal \\
\hline 651 & + & - & 10 & - & Round cells, abnormal buds, chains \\
\hline 659 & Poor & - & 40 & Very poor & Round cells \\
\hline 901 & + & Slow & 60 & Very poor & Round cells \\
\hline 906 & - & Slow & 80 & - & Altered buds, chains \\
\hline 908 & + & - & 60 & - & Chains, multipolar buds \\
\hline 918 & ++ & - & 10 & Partial on lysis & Gigantic cells \\
\hline 933 & + & Slow & 20 & On lysis & Normal \\
\hline 936 & + & + & 60 & - & Normal \\
\hline 938 & - & - & 50 & + & Normal \\
\hline 941 & Poor & - & 40 & - & Chains \\
\hline
\end{tabular}

* Growth was measured by following $\mathrm{OD}_{660} \cdot+$, Wild-type-like growth rates; - , total incapability for growth.

† Approximate percentage of the cells in a culture that do not stain with PI $5 \mathrm{~h}$ after the switch from 24 to $37^{\circ} \mathrm{C}$. The wild-type strain would show a surviving percentage of $99-100 \%$.

$\ddagger$ Complementation of the thermosensitive stopping of growth or cell lysis phenotypes by the addition of $1 \mathrm{M}$ sorbitol as an osmotic stabilizer was never complete. In this table we assign $(+)$ only to those mutants in which both growth and survival rate at restrictive temperatures are appreciably improved by the addition of $1 \mathrm{M}$ sorbitol, but the wild-type phenotype is not recovered in any case.

glusulase was added to $200 \mathrm{ml}$ of the suspension of asci and treated for $10 \mathrm{~min}$. Some crosses between diploid strains were carried out by means of spheroplast fusion using the protocols described by Kakar \& Magee (1982) for Candida albicans.

Flow cytometry. Cells stained with PI (see above) were analysed in a FACSCAN flow cytometer (Becton-Dickinson) as described by De la Fuente et al. (1992) in order to check for cell lysis.

Cellular content of DNA for determining the ploidy of the spheroplast fusion products was also determined by means of flow cytometry. Cells from mid-exponential-phase cultures were collected by centrifugation and fixed by resuspending them in $70 \%(\mathrm{v} / \mathrm{v})$ ethanol for $5 \mathrm{~min}$. Then they were centrifuged again and resuspended in PBS solution supplemented with RNase to a concentration of $1 \mathrm{mg} \mathrm{ml}^{-1}$, and incubated with this enzyme for $30 \mathrm{~min}$ at $37^{\circ} \mathrm{C}$. The cells were finally resuspended in PBS and $0.01 \%$ PI was added. A haploid strain S288C and a diploid strain D1 were utilized as patterns for setting up the machine in linear scale. Tetraploid samples showed a fluorescence signal that doubled the diploid pattern and was four times the haploid pattern signal.

Scanning electron microscopy. Cells for scanning electron microscopy were prepared by filtering $1 \mathrm{ml}$ culture through a $0.2 \mathrm{~mm}$ Millipore filter and fixing the cells with $5 \%(\mathrm{v} / \mathrm{v})$ glutaraldehyde in $0.2 \mathrm{M}$ sodium cacodylate buffer $\mathrm{pH} 7.2$ for $60 \mathrm{~min}$. After this fixation, the filters were washed with the same 
buffer and gradually dehydrated by passing them through graded ethanol concentrations $(25 \%, 50 \%, 70 \%, 90 \%$ and $100 \%, 10 \mathrm{~min}$ in each). Then, the filters were preserved in acetone, dried in a critical-point drier, coated with gold and examined (Williams \& Veldkamp, 1974).

\section{RESULTS AND DISCUSSION}

Studies carried out on thermosensitive autolytic mutants isolated from haploid strains have allowed the identification and characterization of some genes involved in cell wall assembly and stability (Nombela et al., 1993). However, the corresponding mechanisms are complex and the number of genes involved must be high. No studies on the isolation of this type of mutants from diploid strains of $S$. cerevisiae have been reported, but the feasibility of such isolation is clear, as osmotic-remedial autolytic mutants have been isolated from the diploid yeast $C$. albicans (Payton \& de Tiani, 1990). Although the subsequent genetic characterization of mutants isolated from diploids would be more complex than from haploids, we undertook a process of mutagenesis of the diploid strain S. cerevisiae D1, constructed from strains US92-1A and L839 for this work, in an attempt to identify dominant mutations determining an osmotic-remedial thermosensitive autolytic phenotype, as well as to find out if autolysis can be correlated with other alterations, such as inadequate morphogenesis or defects in the cell cycle. It seemed reasonable that this systematic isolation should reveal the main patterns of cell defects in mutants of this type and yield at least some strains amenable to further characterization. Our rationale was that formal genetic analysis of the mutants by segregation and backcrosses should allow us to correlate some of the mutant phenotypes with genetic alterations. The interest of some of the putative dominant mutations could justify attempts to clone the corresponding gene, for example, by developing gene banks, from the mutant strain, for transforming wild-type cells, and by screening for transformants with the same phenotypic defect as the corresponding dominant mutant.

The phenotypic characterization included the extent of osmotic remediation of the autolytic defect as well as the analysis of alterations in cell morphology determined by the mutation. Survivors of the mutagenesis were plated and 13300 colonies were obtained to be processed as described in Methods. A total of 183 clones were initially selected as potential thermosensitive autolytic mutants. All of these clones were reexamined by growing them in $5 \mathrm{ml}$ YEPD medium tubes at $24^{\circ} \mathrm{C}$, followed by a switch to $37^{\circ} \mathrm{C}$ when mid-exponential phase was reached. The mutants were again checked by PI staining of samples taken at intervals, during a $24 \mathrm{~h}$ period at the nonpermissive temperature, autolysis being followed by FACS analysis of the stained samples (De la Fuente $e t a l$., 1992). This screening yielded 34 thermosensitive mutants which showed a cell lysis, indicated by PI staining, at least 10-fold higher than the lysis shown by the wild type strain D1. The main features of the mutants are shown in Table 2 and commented on below.

\section{Cell lysis and osmotic remediation}

In order to identify those mutants that were osmoticremedial, we measured growth and lysis of the resultant strains at the non-permissive temperature in the presence of $1 \mathrm{M}$ sorbitol. Seven of the mutant strains were stabilized in $1 \mathrm{M}$ sorbitol to some extent, with regard to both growth and lysis. The other strains were either not complemented by the osmotic stabilizer or very poorly and/or partially complemented either for growth or for lysis.

Although none of the mutants showed complete osmotic remediation of the autolytic phenotype, a general improvement of either or both cell growth and lysis was observed in several mutants. For example, in strain 933 the percentage of lysed cells was reduced to half its former value when cells were grown at $37^{\circ} \mathrm{C}$ in stabilized medium, though the growth rate did not improve. Other osmotic stabilizers, like $0 \cdot 1 \mathrm{M} \mathrm{CaCl}_{2}$, were tested, yielding similar results (data not shown). These results imply that one or several mutations that might be determinants of the phenotype of the different mutants eventually lead to a loss of cell wall integrity, thus necessitating osmotic stabilization of the cell to prevent lysis. The genetic defect could affect functions involved in the generation of the cell wall architecture either directly or in a pleiotropic manner.

In many of the mutants, we observed a partial complementation of either autolysis or growth defects by the osmotic stabilization with $1 \mathrm{M}$ sorbitol. To interpret these results it should be also taken into account that $1 \mathrm{M}$ sorbitol has a negative effect on growth of even wild-type strains: growth is slightly slower in the presence of this stabilizer, and the stationary phase is reached at slightly lower cell concentrations. In any case, the growth rate of the mutant strains 201 and 356 improved when sorbitol was added, without any variation in the percentage of PI-

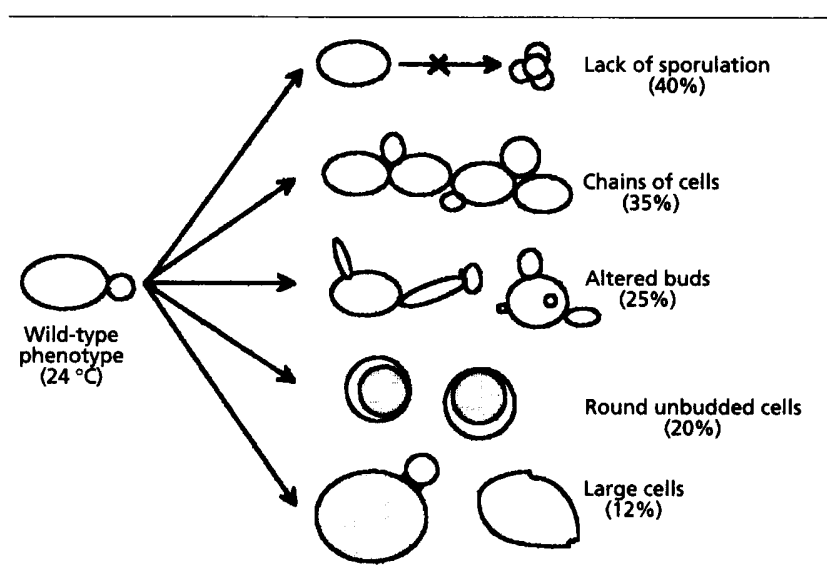

Fig. 1. The most common morphological changes observed in our diploid autolytic thermosensitive mutants after the switch to a non-permissive temperature $\left(37^{\circ} \mathrm{C}\right)$. Only $20 \%$ of the different mutants lysed without showing any changes in morphology. The high proportion of the strains that are unable to sporulate is remarkable. 

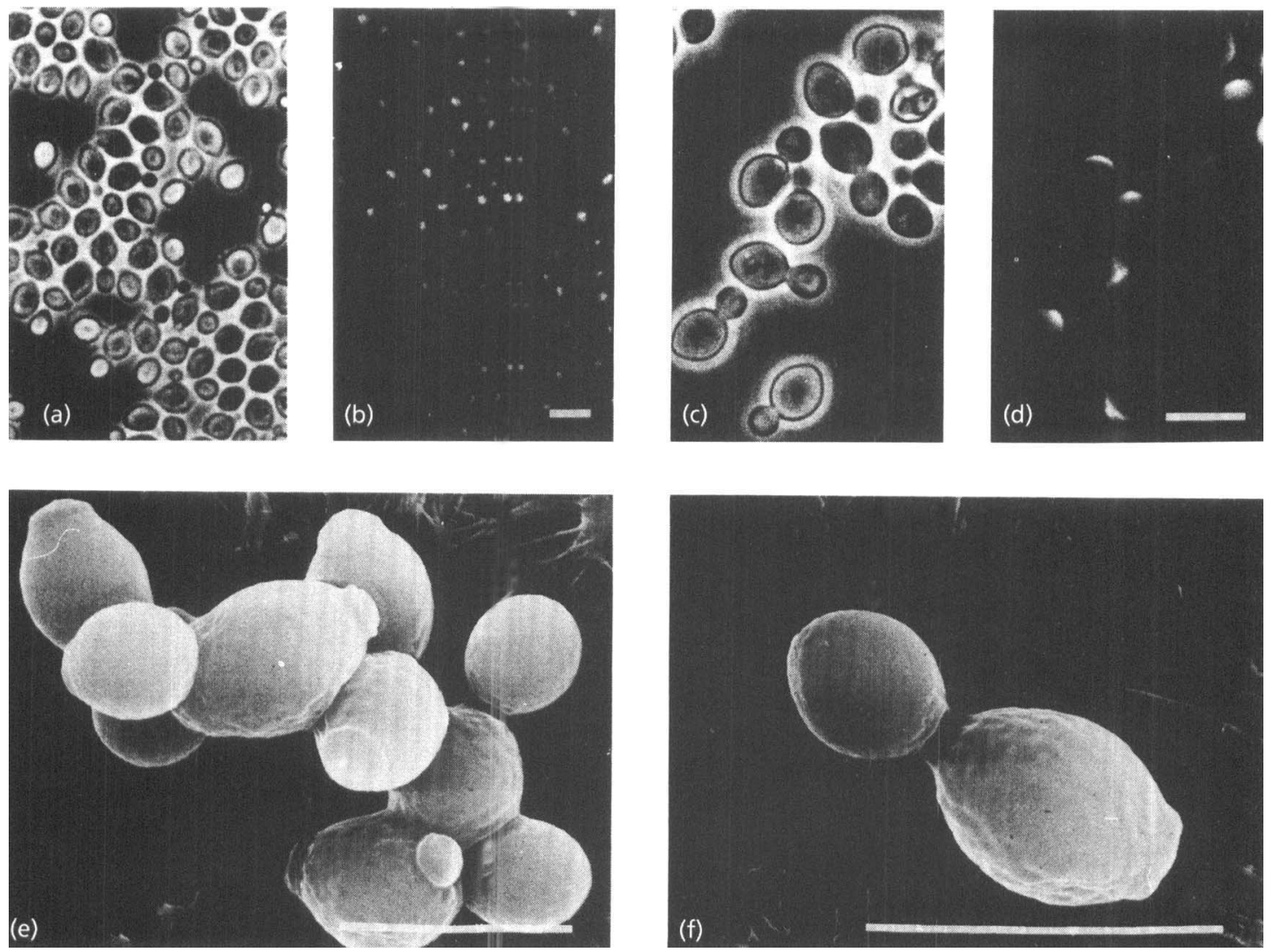

Fig. 2. Wild-type strain D1. (a) and (b) show the same field respectively under phase-contrast and fluorescence microscopy after staining with chromomycin. Each cell shows only one nucleus. (c) and (d) show the same comparison, but staining has been performed with calcofluor white in order to study the distribution of cell wall chitin. This polymer is clearly located at the mother-daughter junction. (e) and ( $f$ ) are scanning electron micrographs: (e) shows a group of aggregated cells, while (f) shows an isolated cell budding distally from its birth scar, a typical feature of yeast diploid cells. Bars, $5 \mu \mathrm{m}$.

stained cells, therefore without affecting the percentage of lysed cells. Cell growth involves morphogenetic mechanisms for bud development, including those related to cell wall synthesis and turnover. Mutations affecting these morphogenetic mechanisms or their regulation should cause lytic phenotypes. The most striking aspect of our results is the heterogeneity shown by the different mutants, regarding growth, lysis and morphology. It is thus clear that the pathways connecting cell growth control, cell wall integrity and morphogenesis must be complex and varied. In agreement with such complication is the great variety of genes that are identified by different laboratories as being related to these morphogenetic pathways (see Madden $e t$ al., 1992, for a review).

Approximately half of our isolated mutant strains were completely unaffected by the presence of osmotic stabilizers. Multiple cell dysfunctions must therefore exist that lead to cell lysis independently of the osmotic environment. These non-osmotic-remediable mutants might be considered as being affected, for example, in functions related to membrane formation, secretion pathways, osmohomeostatic regulation or in any other process not directly involved in the generation of cell wall architecture. However, it is also conceivable that some of them have a failure in some essential requirement for cell wall formation which cannot be remedied in osmotically stabilized medium.

\section{Abnormal morphologies of some of the autolytic mutants}

Another salient feature in many of the mutant phenotypes was an alteration in cell morphology. Morphological alterations observed in the mutants are depicted in Fig. 1: $40 \%$ of them were deficient in sporulation, $35 \%$ of them often grew in chains of cells, $25 \%$ gave rise to buds altered in their morphology, 20\% originated round, unbudded and highly vacuolated cells and $12 \%$ simply gave rise to large-sized cells. These morphologies can be compared with the morphology of the wild-type strain (Fig. 2).

Several mutants displayed cells in chains, presumably due to a defect in cytokinesis or cell separation at the latest stages of the cell cycle. Haploid disruptants of the CTS1 

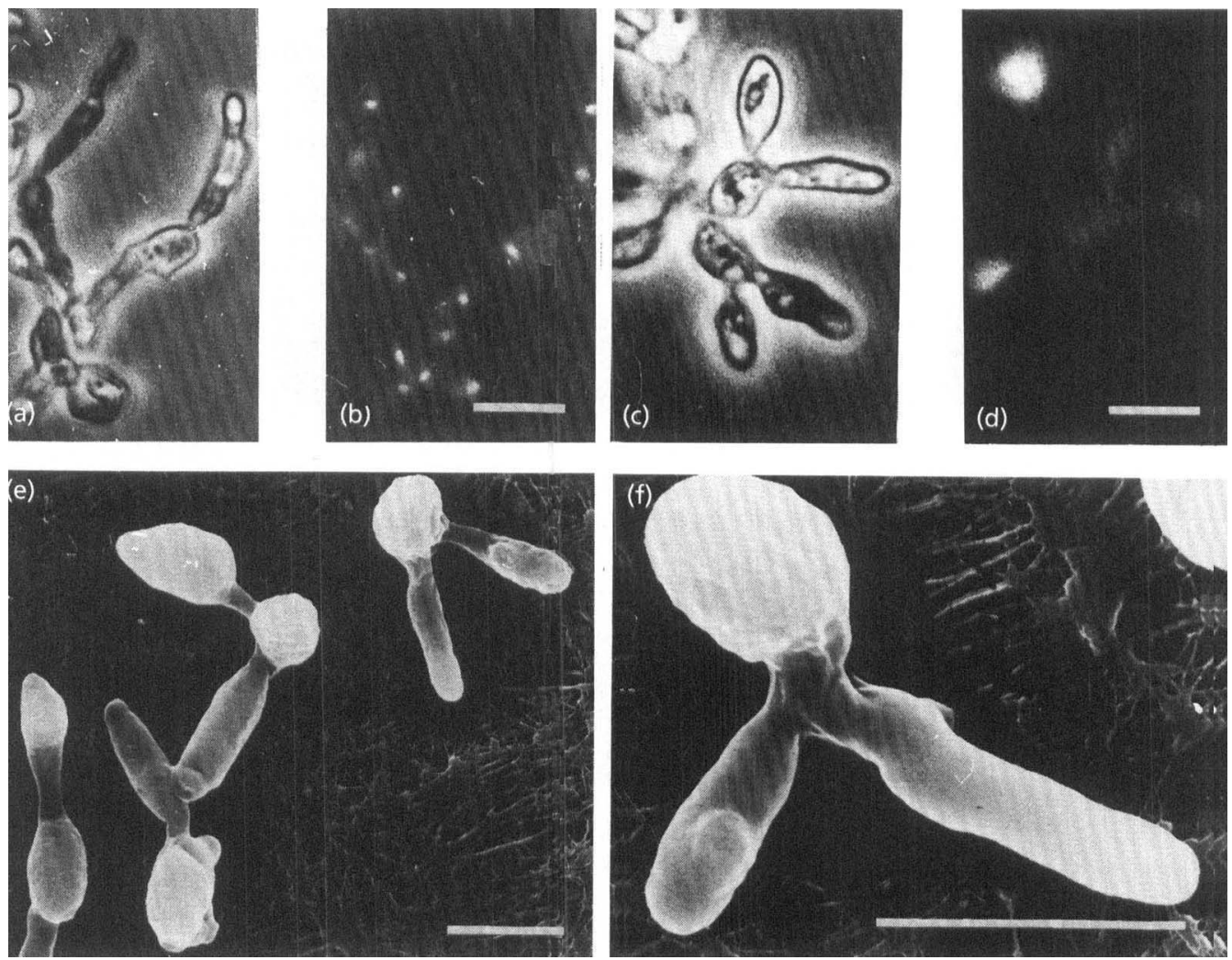

Fig. 3. Characteristics of the mutant strain 327 , which develops elongated abnormal buds. (a) and (b) (conditions as in Fig. 2) show that the distribution of nuclei along the pseudohyphal branches is not random. The darker branch in (a) shows no DNA content in (b), as it has already lysed and emptied. Chitin distribution, as shown in (c) and (d) (conditions as in Fig. 2), is irregular, being sometimes evenly distributed, though areas rich in chitin are still found around the putative septum and at the tip of some of the elongated buds. (e) and (f) show scanning images of the peculiar phenotype of this mutant after $5 \mathrm{~h}$ at the non-permissive temperature. Bars, $5 \mu \mathrm{m}$.

gene have been reported to be deficient in cell separation (Kuranda \& Robbins, 1991). In our mutants mother and daughter cells seemed to initiate a cell division round without separating from each other, and this phenomenon went on until a more or less branched chain was formed. Several among the mutants showing this phenotype, for example 238, 623 and 908 , did not give rise to chains longer than four to six cells. In most cases, these chains were formed even when the cells grew at the permissive temperature of $24^{\circ} \mathrm{C}$. After the switch to $37^{\circ} \mathrm{C}$, lysis exclusively affected the chained cells, while cells that managed to separate could undergo a complete division, so a progressive recovery of growth and normal shape was observed. Eventually, after $24 \mathrm{~h}$ at $37^{\circ} \mathrm{C}$, normal growth was attained in these strains. Under such circumstances, PI staining of a proportion of the cells, especially the chained ones, was apparent initially at the non-permissive temperature, but it gradually disappeared as healthy cells developed. Such a situation originated a period of latency after the thermal switch preceding a restart of growth. This lag period was different in length depending on the mutant (data not shown), but it always led to a more or less normal active growth phase and ended in an apparently normal stationary phase. In order to check that the recovery of the cells was not due to genetic reversion, we plated the cells after the $24 \mathrm{~h}$ period at $37^{\circ} \mathrm{C}$, and tested the corresponding colonies. We confirmed that the clones obtained maintained the phenotype and gave rise to cultures at $24^{\circ} \mathrm{C}$ and $37^{\circ} \mathrm{C}$ that behaved like the previous ones. The interpretation of these results is not easy. It is conceivable that the mutations could affect some cellular function essential for normal growth, hence the lethal phenotype that many of the cells expressed upon the temperature switch. However, individual differences among cells might cause some of them to escape the lethality, to persist and grow, leading to a recovery of the culture. Alternatively, leakiness of the mutations might permit the recovery.

Mutant strains 332, 618, 643 and 941 also shared some of these characteristics, but the chains formed were longer, often stemming from a central cell in many directions. This central cell was the first to lyse, and lysis seemed to progress from the older cells to younger ones in the chain. In these four mutants, lysis also affected cells in chains predominantly, but in survivor isolated cells growth was not restored at $37^{\circ} \mathrm{C}$. In spite of the common behaviour of the chained mutants, important differences existed 

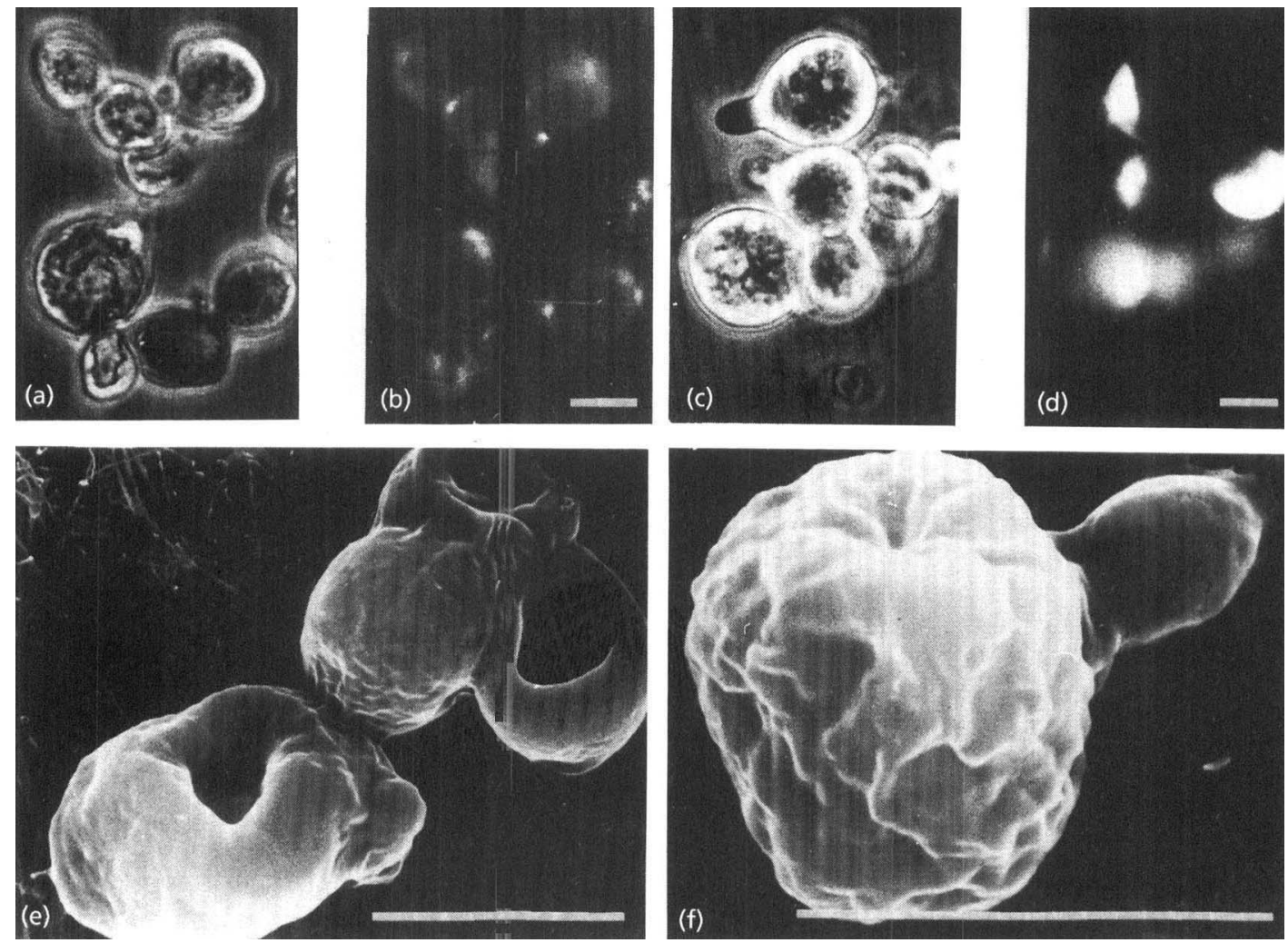

Fig. 4. Characteristics of the mutant strain 918. (b) and (d) show nuclei and chitin staining respectively, while (a) and (c) show the phase-contrast image for the corresponding fields. The large fragile cells that characterize this mutant show more than one nucleus and the area embraced by the chitin ring is wider than that in the wild-type, sometimes covering half the cell surface. The scanning image of a $37^{\circ} \mathrm{C}$ culture after $5 \mathrm{~h}(\mathrm{e})$ shows empty dead cells or 'ghosts'. Surviving cells often show an abnormally rough surface (f). Bars, $5 \mu \mathrm{m}$.

among them. Chains were often accompanied by other morphogenetic defects, such as abnormal cell size or bud morphology. In the mutants in which these defects were severe, lysis generalized to the whole population and growth at $37^{\circ} \mathrm{C}$ was not recovered.

Another outstanding morphological defect found in this set of mutants was the formation of abnormally elongated buds. This was most pronounced in strain 327, which at non-permissive temperature developed double elongated buds that continued to grow by developing pseudohyphal-like structures until lysis occurred (Fig. 3). Abnormally elongated cells were also observed in strains 235 and 623. As with the chained cells of some mutants, the elongated structures in these two mutants were observed at $24^{\circ} \mathrm{C}$ and disappeared after the switch to $37^{\circ} \mathrm{C}$, being replaced by normal non-lysing ovoid cells. Elongation was not as severe as that observed for buds of strain 327, but appreciable when compared to wild-type cells. Cells of strain 335 were thin and elongated, while those of strain 623 were oblong and large.

Abnormally large cells were also observed as another morphological phenotype displayed by some of the mutant strains. This phenotype was extreme in strain 918 (Fig. 4), whose round cells increased their size 3- to 10- fold after the thermal switch. Lysis in this strain was also severe at $37^{\circ} \mathrm{C}$. These huge rounded or aberrant cells displayed large vacuoles, that could be observed by phasecontrast microscopy, and a wrinkled surface clearly apparent by scanning electron microscopy. Many of the large rounded cells showed small, characteristic thimbleshaped buds. The corresponding cells carried two or three nuclei. The survivor non-lysed cells at $37^{\circ} \mathrm{C}$ were the ones that had grown to very large sizes without displaying any sign of bud initiation whereas only budded cells were lysed. Calcofluor staining of this mutant showed that chitin embraced an area larger than usual, extending from the septum zone to a more or less spread hemisphere around the mother cell wall. With only these observations it is not possible to establish whether the abnormal chitin distribution is directly related to the mutation and responsible for the morphological defect or, rather, is an indirect consequence of the alteration of some other function by the mutation. These alterations could be the consequence of a defect in cell division leading to multinucleate cells that seemed unable to develop their buds properly.

Some mutations seemed to affect cell integrity without affecting morphogenetic pathways; lysis in these mutants 

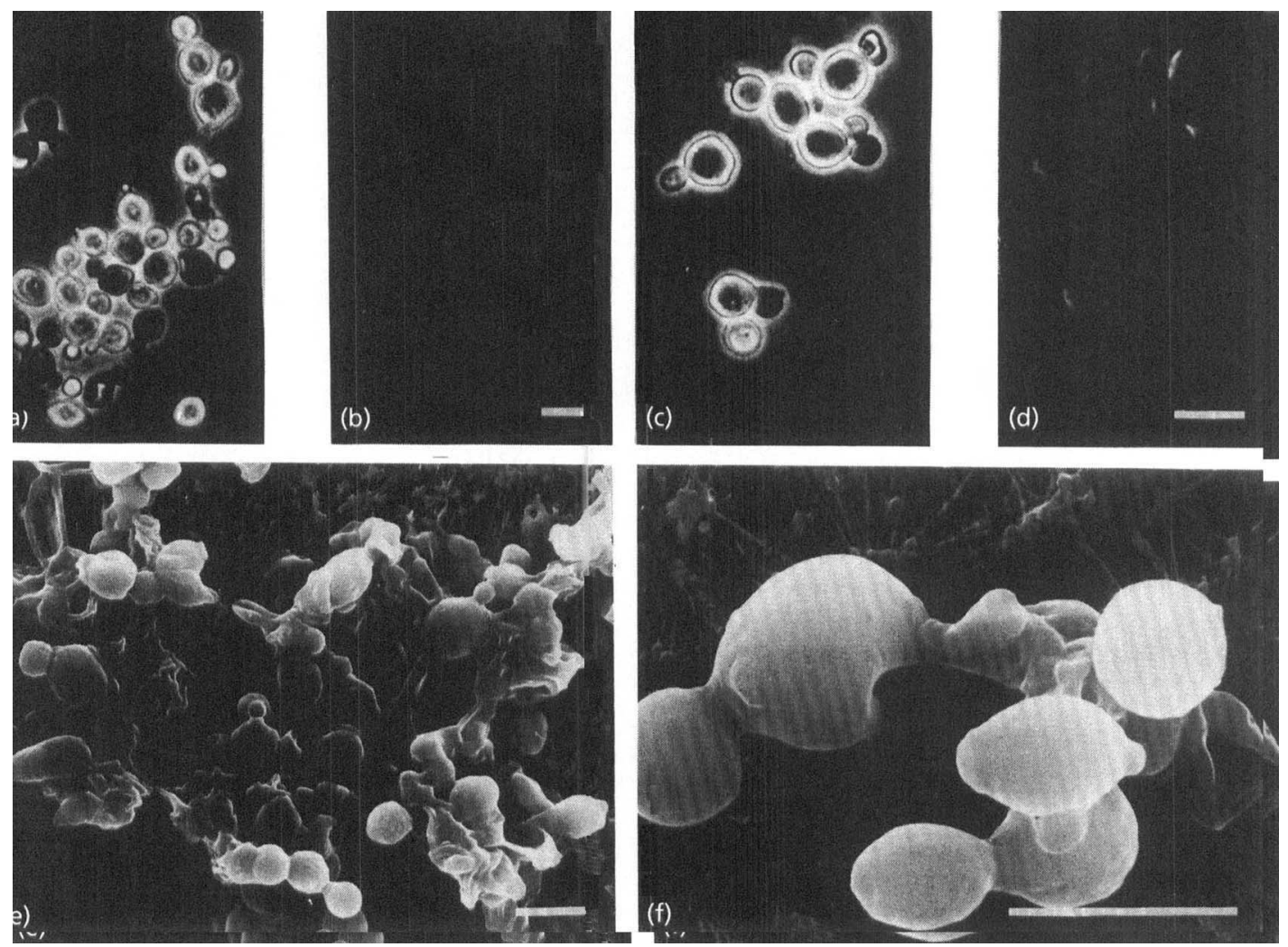

Fig. 5. Characteristics of the mutant strain 933. The morphology is not abnormal in this mutant, but most cells lyse after the switch to $37^{\circ} \mathrm{C}$. Each cell carries a single nucleus, though it is not visible in dead empty cells, as can be seen in fields (a) and (b), showing a phase-contrast image and corresponding fluorescent nuclei staining, respectively. Fields (c) and (d) show that chitin appears in the normal place. The scanning electron micrographs (e) and (f) of the cells after $5 \mathrm{~h}$ incubation at the non-permissive temperature reveal a great proportion of lysed empty cells. Bars, $5 \mu \mathrm{m}$.

was not accompanied by the formation of aberrant shapes. Strain 933 is a clear example (Fig. 5), and it is reminiscent of haploid mutants such as those carrying the slt 2 trait (Torres et al., 1991). Strains 628, 630, 936 and 938 also lysed, though to a lesser extent, without altering their morphology. Mutants 111 and 201 were seriously impaired in growth, even at $24^{\circ} \mathrm{C}$, and their inability to grow at the permissive temperatures made it impossible to carry out further studies in these strains. A peculiar mutant because of its homogeneity is 642 . Its aspect was like the wild-type strain, except for the abundance of halfsized, lysed cells rich in nucleic acids. After switching a culture of this strain to $37^{\circ} \mathrm{C}$ the culture grew at a slightly slower rate than the wild-type. Normal-sized cells never lysed, so this mutation(s) might cause a premature separation and death of the daughter cell.

\section{Genetic analyses of some of the strains}

The main objective of this research was to identify dominant mutations, but some of the mutants obtained were likely to carry more than one recessive or dominant mutation, the observed phenotype being a result of the superposition of several genetic defects. Therefore, the dominance or recessiveness of these mutations should be tested by crossing their haploid segregants with wild-type strains. A genetic analysis was performed with strains 618 , 651, 933 and 918.

Sporulation of strain 618 , one of the chained mutants described above, yielded a 3:1 ratio of lytic:non-lytic progeny, indicating that more than one mutation was determining the mutant phenotype. Some of the haploid segregants displayed a more aberrant morphology than the parental diploid. Crosses of these haploid segregants from strain 618 with the wild-type strain 373 led to wildtype diploids, showing that the individual mutations were recessive. These new wild-type diploids yielded a $2: 2$ ratio of offspring in most cases.

Segregants from strain 651 were non-viable in a high proportion so most tetrads yielded two or three spores. Although a complete tetrad was never obtained, among survivors there were wild-type and mutant haploid cells. Crossing the 651 haploid segregants to both wild-type strains 373 and L839 yielded new thermosensitive autolytic diploids, so the mutation should have been dominant in this case. Nevertheless, these new diploids were not able to develop analysable offspring, because the spores were seldom viable. We conclude that this mutation somehow affects spore viability. 
Segregation in strain 918 was $4: 0$, all of the haploids being lytic in 10 dissected tetrads. The most obvious straightforward explanation is that a mutation was affecting both alleles of the same gene, but the likelihood of this occurring in our mutagenesis is remote; thus, perhaps less obvious explanations should be considered. Crossing these haploid mutants with strain 373 yielded a wild-type diploid, showing that the mutation was recessive. The offspring of this second diploid, and even a third generation achieved by crossing them again with 373 , were studied, and though the predominant segregation pattern was $2: 2$, their phenotypes were not uniform in the abundance of aberrant cell types and growth rates, thus showing a strong dependence on their genetic background.

Sporulation of strain 933 clearly gave a $2: 2$ viable: nonviable segregation. The frequency of reversion of this mutant was high. We conclude that the mutation responsible for the lytic phenotype in the diploid either was lethal for haploids or prevented spore germination.

Many of the mutants isolated were unable to sporulate. This is not surprising if we assume that some relationship might exist between the mechanisms involved in preserving cell integrity and directing morphogenesis and those controlling spore formation. The lack of sporulation prevented any genetic analysis of segregants in some of our most interesting mutants. Therefore, in order to find out if the mutations borne by strains unable to sporulate were dominant in the presence of wild-type copies of the gene, we decided to cross these diploids to the wild-type diploid DV373, constructed for this work from strains S288C and 373, by means of protoplast fusion. The DNA content of the resultant tetraploids was confirmed by flow cytometry (see Methods), and their behaviour at the nonpermissive temperature checked and compared with the wild-type tetraploid strain D1 $\times$ DV373.

The tetraploids $201 \times$ DV373, $327 \times$ DV 373 and $933 \times$ DV373 were lytic, indicating that the corresponding mutations were dominant. The dominance of the mutation in strain 933 was also suggested by the segregation in haploids (see above). The tetraploid $918 \times 373$ also lysed considerably, though it had been characterized before as recessive (see above).

We conclude that the systematic search for mutants from a diploid strain does lead to some clones that bear a complex set of mutations, but their exploration also makes it possible to identify mutations that are dominant, such as the one observed in strain 933, which otherwise would have been impossible to obtain. The screening described above reflects the variety of morphological alterations that can occur in autolytic mutants. The most remarkable ones are shown by strains 327 and 918 (Figs 3 and 4). The phenotype exhibited by strain 327 resembles that of the mutants in which the putative $10 \mathrm{~nm}$ microfilament ring components $\mathrm{CDC} 3, \mathrm{CDC} 10, \mathrm{CDC11}$ and CDC12 are affected (Ford \& Pringle, 1991; Kim et al., 1991). On the other hand, a very similar phenotype to that shown by strain 918 has been reported when the catalytic subunits of $S$. cerevisiae major protein phosphatase $2 \mathrm{~A}$ are highly overexpressed (Ronne et al., 1991), and large unbudded cells are also patent in mutants defective in bud emergence (Bender \& Pringle, 1991).

The interest of autolytic mutants is multiple and is based on both the identification of critical functions for cell wall integrity and on the potential use of these strains for biotechnological processes, such as the release of proteins from yeast cells (De la Fuente et al., 1993). Our efforts will continue to be directed to the characterization of some of these strains, including the molecular cloning of some of the genes involved.

\section{ACKNOWLEDGEMENTS}

This investigation was supported by grant PB91-919-01 from Dirección General de Investigación Científica y Técnica (MEC), Spain and grant BIOT-CT90-0165 from the Commission of the European Community (BRIDGE programme). We thank $\mathrm{Mr}$ Alberto Alvarez for his valuable help with the cytometric techniques.

\section{REFERENCES}

Bender, A. \& Pringle, J. R. (1991). Use of a screen for synthetic lethal and multicopy suppressor mutants to identify two new genes involved in morphogenesis in Saccharomyces cerevisiae. Mol Cell Biol 11, 1295-1305.

Borgia, P. B. \& Dodge, C. L. (1992). Characterization of Aspergillus nidulans mutants deficient in cell wall chitin or glucan. $J$ Bacteriol 174, 377-383.

Brewster, J. L., de Valoir, T., Dwyer, N. D., Winter, E. \& Gustin, M. C. (1993). An osmosensing signal transduction pathway in yeast. Science 259, 1760-1763.

Cabib, E. \& Duran, A. (1975). Simple and sensitive procedure for screening yeast mutants that lyse at non-permissive temperatures. J Bacteriol 124, 1604-1606.

Costigan, C., Gehrung, S. \& Snyder, M. (1992). A synthetic lethal screen identifies $S L K 1$, a novel protein kinase homolog implicated in yeast cell morphogenesis and cell growth. Mol Cell Biol 12, 1162-1178.

De la Fuente, J. M., Vazquez, A., Nombela, C. \& Sanchez, M. (1992). Flow cytometric analysis of Saccharomyces cerevisiae autolytic mutants and spheroplasts. Yeast 8, 39-45.

De la Fuente, J. M., Vazquez, A., Gonzalez, M. M., Sanchez, M., Molina, M. \& Nombela, C. (1993). Expression of mutations and protein release by yeast conditional autolytic mutants in batch and continuous cultures. Appl Microbiol Biotechnol 38, 763-769.

Ford, S. K. \& Pringle, J. R. (1991). Cellular morphogenesis in the Saccharomyces cerevisiae cell cycle: localization of the CDC11 gene product and the timing of events at the budding site. Dev Genet 12, 281-292.

Kakar, S. N. \& Magee, P. T. (1982). Genetic analysis of Candida albicans: identification of different isoleucine-valine, methionine and arginine alleles by complementation. $J$ Bacteriol 151, 1247-1252.

Kim, H. B., Haarer, B. K. \& Pringle, J. R. (1991). Cellular morphogenesis in the Saccharomyces cerevisiae cell cycle: localization of the $C D C 3$ gene product and the timing of events at the budding site. J Cell Biol 112, 535-544.

Kuranda, M. J. \& Robbins, P. W. (1991). Chitinase is required for cell separation during growth of Saccharomyces cerevisiae. J Biol Chem 266, 19758-19767. 
Lee, K. S. \& Levin, D. E. (1992). Dominant mutations in a gene encoding a putative protein kinase ( $B C K 1)$ bypass the requirement for a Saccharomyces cerevisiae protein kinase $\mathrm{C}$ homolog. Mol Cell Biol $12,172-182$.

Lee, K. S., Irie, K., Gotoh, Y., Watanabe, Y., Araki, H., Nishida, E., Matsumoto, K. \& Levin, D. E. (1993). A yeast MAP kinase homolog (MPK1) mediates signaling by protein kinase C. Mol Cell Biol 13, 3067-3075.

Levin, D. E., Fields, F. O., Kunisawa, R., Bishop, J. M. \& Thorner, J. (1990). A candidate protein kinase gene, $P K C 1$, is required for the Saccharomyces cerevisiae cell cycle. Cell 62, 213-224.

Madden, K., Costigan, C. \& Snyder, M. (1992). Cell polarity and morphogenesis in Saccharomyces cerevisiae. Trends Cell Biol 2, 22-29.

Martin, H., Arroyo, J., Sanchez, M., Molina, M. \& Nombela, C. (1993). Activity of the yeast MAP kinase homologue Slt2 is critically required for cell integrity at $37^{\circ} \mathrm{C}$. Mol \& Gen Genet 241, 177-184.

Nombela, C., Molero, G., Martin, H., Cenamor, R., Molina, M. \& Sanchez, M. (1993). Genetic control of fungal cell wall autolysis. In Bacterial Growth and Lysis: Metabolism and Structure of the Murein Sacculus pp. 285-294. Edited by M. A. de Pedro, J. V. Höltje \& W. Löffelhardt. London: Plenum Press.

Paravicini, G., Cooper, M., Friedli, L., Smith, D. J., Carpenter, J. L., Klig, L. S. \& Payton, M. (1992). The osmotic integrity of the yeast cell requires a functional $P K C 1$ gene product. Mol Cell Biol 12, 4896-4905.

Payton, M. \& de Tiani, M. (1990). The isolation of osmotic- remedial conditional lethal mutants of Candida albicans. Curr Genet 17, 293-296.

Ribas, J. C., Diaz, M., Duran, A. \& Perez, P. (1991). Isolation and characterization of Scbizosaccharomyces pombe mutants defective in cell wall (1-3) $\beta$-D-glucan. $J$ Bacteriol 173, 3456-3462.

Roncero, C., Valdivieso, M. H., Ribas, J. C. \& Duran, A. (1988). Effect of calcofluor white on chitin synthases from Saccharomyces cerevisiae. J Bacteriol 170, 1945-1949.

Ronne, H., Carlberg, M., Hu, G. Z. \& Nehlin, J. O. (1991). Protein phosphatase 2A in Saccharomyces cerevisiae: effects on cell growth and bud morphogenesis. Mol Cell Biol 11, 4876-4884.

Torres, L., Martin, H., Garcia-Saez, M. I., Arroyo, J., Molina, M., Sanchez, M. \& Nombela, C. (1991). A protein kinase gene complements the lytic phenotype of Saccharomyces cerevisiae lyt2 mutants. Mol Microbiol 5, 2845-2854.

Stateva, L. I., Oliver, S. G., Trueman, L. J. \& Venkov, P. V. (1991). Cloning and characterization of a gene which determines osmotic stability in Saccharomyces cerevisiae. Mol Cell Biol 11, 4235-4243.

Venkov, P. V., Hadjiolov, E., Battaner, E. \& Schlessinger, D. (1974). Saccharomyces cerevisiae sorbitol dependent fragile mutants. Biochem Biophys Res Commun 56, 559-604.

Williams, S. T. \& Veldkamp, C. I. (1974). Preparation of fungi for scanning electron microscopy. Trans Br Mycol Soc 63, 409-412.

Received 9 March 1993; revised 30 July 1993; accepted 23 September 1993. 